\title{
GEMEINHARDT, Peter, Das lateinische Christentum und die antike pagane Bildung
}

\section{Michel Banniard}

\section{OpenEdition}

\section{Journals}

Édition électronique

URL : http://journals.openedition.org/ifha/1762

DOl : 10.4000/ifha. 1762

ISSN : 2198-8943

Éditeur

IFRA - Institut franco-allemand (sciences historiques et sociales)

Référence électronique

Michel Banniard, « GEMEINHARDT, Peter, Das lateinische Christentum und die antike pagane Bildung », Revue de l'IFHA [En ligne], Date de recension, mis en ligne le 01 janvier 2009, consulté le 22 septembre 2020. URL : http://journals.openedition.org/ifha/1762 ; DOI : https://doi.org/10.4000/ifha.1762

Ce document a été généré automatiquement le 22 septembre 2020

(CIFHA 


\title{
GEMEINHARDT, Peter, Das lateinische Christentum und die antike pagane Bildung
}

\author{
Michel Banniard
}

Cet épais volume a un statut universitaire particulier : il est la mise en forme d'une thèse soutenue pour une habilitation à la Faculté de Théologie Friedrich-Schiller d'Iena, comme l'indique opportunément son auteur (p. VII), qui est devenu depuis professeur d'Histoire de l'Église dans cette université. Compte tenu de la jeunesse de P.G. (il est né en 1970), la première impression est tout à fait favorable devant l'ampleur de la documentation rassemblée. La seconde l'est un peu moins, parce qu'il ne s'agit pas d'un travail original de recherche, comme le requiert la recherche universitaire laïque. On ne voit d'ailleurs pas comment cela aurait été possible sur un sujet immense, couvrant toute l'Antiquité Tardive, même limitée à sa zone latinophone (en dépit de nombreuses références au domaine grec) ! Il sera plus raisonnable de juger cet ouvrage comme un cours spécialisé d'histoire consacré, comme le dit son titre, aux rapports entre " la Chrétienté latine et la culture païenne antique ». Et à ce compte, nous disposons là d'un ouvrage complet et clair, bien construit, truffé d'innombrables citations latines (et grecques, parfois) traduites dans le corps du texte, mais disponibles commodément en bas de notes (même si par la force du genre, la majorité des textes invoqués était déjà bien connue des spécialistes).

Le plan est purement chronologique : Introduction (p. 1-24) ; I. Les institutions culturelles de l'Empire romain (p. 27-62) ; II. La chrétienté et la culture à l'époque préconstantinienne (p. 63-128) ; III. La chrétienté et la culture dans l'Antiquité Tardive (p. 129-487) ; Résumé et conclusions (p. 488-512). Une bibliographie étendue (p. 513-548) et des index (p. 549-594) clôturent l'ouvrage. Précisons que le texte est fort dense avec une impression en corps serré et que des notes de bas de page copieuses (essentiellement des citations d'auteurs antiques), enrichissent et confortent l'information. On voit bien que ce professeur de théologie est familier depuis longtemps de ces problèmes, des textes clefs qui en traitent et du consensus qui a fini par se dégager chez les spécialistes de la période, hellénistes, latinistes, patristiciens et 
historiens. L'idée majeure, désormais bien implantée, est que le conflit aigu initial engagé avec la culture et l'école des païens s'est transformé en une osmose profonde avec le dogme, l'enseignement et la religion chrétiennes au point de construire une nouvelle culture, à la fois héritière et distincte du passé.

L'extrême généralité du propos a entraîné évidemment le recours à une bibliographie elle-même générique allant parfois jusqu'à l'énumération des usuels de toute bonne bibliothèque d'un département de latin (p. 514-515) ! On s'étonnera inversement d'absences tout de même regrettables (parmi lesquelles à titre d'exemple : M. Banniard, Viva voce. Communication écrite et communication orale du IVe au IXe siècle en Occident Latin, Paris, 1992 ; P. Brown, The Making of Late Antiquity, Berkeley, 1978; id., The cult of the saints. Its rise and function in latin christianity, Chicago, 1981; B. Dumézil, Les racines chrétiennes de l'Europe. Conversion et liberté dans les royaumes barbares (Ve-VIIIe s.), Paris, 2005 ; F. Graus, Volk, Herrscher und Heiliger im Reich der Merowinger, Prague, 1965; Dag Norberg, Manuel pratique de latin médiéval, Paris, 1968 ; G. Philippart, Les légendiers latins et autres manuscrits hagiographiques, Turnhout, 1977 ; id., «L'hagiographie, histoire sainte des "amis de Dieu" » in : Hagiographies, t. 4, 2006, p. 13-40 ; M. Van Uytfanghe, "Le latin des hagiographes mérovingiens et la protohistoire du français » in : Romanica Gandensia, t. 16, 1976, p. 5-89 ; id., « La Bible et l'instruction des laïcs à l'époque mérovingienne : des témoignages textuels à une approche langagière de la question " in : Sacris erudiri, t. 34, 1994, p. 67-123). Précisément, sur la question du dialogue entre les méthodes de la rhétorique païenne et les exigences de la prédication chrétienne, l'auteur reprend à ses frais le dossier. La démarche est sans doute méritoire à titre individuel, mais elle est dommageable pour la recherche - voire pour l'Histoire de l'Église, puisque l'auteur ne tient aucun compte de l'abondante production scientifique qui, depuis plus de trente ans, s'est penchée sur le domaine passablement complexe des modes par lesquels et surtout des langues dans lesquelles l'élite ecclésiale a instruit les fidèles pendant des siècles. Les p. 308 (sur Grégoire I et la grammaire), 337 (sur Augustin et l'éloquence chrétienne), etc. n'apportent aucune avancée faute de cet appui. De même de très nombreux passages ne sont souvent que de longs montages de textes à peine paraphrasés (ainsi p. 254-257, à propos d'Antoine, sur la culture monacale ; p. 329, sur l'éloquence d'Ambroise...).

Il est en fait fort difficile de jauger ce travail à l'aune de la recherche au sens strict. Je ferai quand même quelques remarques sur le fond. D'abord, globalement, l'auteur est sans doute un peu optimiste : il sous-estime deux résistances, celle d'une part des élites païennes qui n'ont pas rendu les armes si facilement que cela (il suffit de lire Ammien Marcellin, Zosime et... G. Sabbah, La méthode d'Ammien Marcellin, Paris, 1978, ou F. Paschoud, Roma aeterna, Etudes sur le patriotisme romain dans l'Occident Latin à l'époque des grandes invasions, Rome, 1967), celle d'autre part des masses dont la conversion s'est accompagnée souvent de nombreux compromis avec les traditions, les coutumes, les superstitions païennes (pas toujours détectables ou reconnaissables). Ensuite, dans ses conclusions générales, l'auteur me paraît tout de même contracter excessivement la problématique.

L'ampleur du sujet le contraignait certes à des raccourcis, mais c'est un peu ennuyeux de lire des phrases comme "Tertullien avait catégoriquement refusé qu'un Chrétien soit professeur, alors que la Traditio apostolica était déjà prête à des concessions... » (p. 490), alors que les travaux de J.-C. Fredouille, pourtant cité, offraient un tableau bien plus nuancé. On doutera aussi quelque peu des considérations trop rapides sur Jérôme (p. 492) dont la prédilection pour l'elegantia classique et le goût pour le latin complexe 
ne se démentent jamais dans les faits, quelles que soient ses déclarations de vertu effarouchée (l'accumulation de testimonia par $\mathrm{H}$. Hagendahl a conduit ce dernier à noyer le poisson). On s'étonnera surtout des considérations de la p. 501, exposant que " les écrits hagiographiques des IVe et Ve siècles qui nous sont parvenus attestent d'un projet littéraire contraignant, alors que ceux du VIe siècle se détachent de plus en plus des représentations populaires ". Qu'entend l'auteur par "représentations »? Les réalités décrites ? Le mode narratif ? Le langage employé ? Le recenseur émettra alors les plus vives réserves sur ce prétendu éloignement. Même réserve devant l'affirmation p. 508 : « Là où au contraire la culture se concentre dans entourage spécifique à la lecture de la Bible (c'est à dire dans un contexte proprement chrétien), de telles compétences grammaticales et rhétoriques n'avaient aucun rôle à jouer (le Vivarium de Cassiodore est sur ce point une singularité) ». Le recenseur ne peut pas entrer plus loin dans la discussion ici, mais ces affirmations lui paraissent (sauf erreur de compréhension de sa part), tenir peu compte des réalités sociolinguistiques de la matière ainsi traitée. Cela appert d'abord a priori de la réalité d'un savoir écrit, forcément savant, parce que demandant une maîtrise langagière réelle; ensuite d'une lecture plus patiente des œuvres clefs d'Augustin, voire d'Ambroise ; enfin des apports d'éminents patristiciens "laïques" comme Fontaine (cité, mais apparemment peu lu), Holz, Marrou ou Nauroy. Mais c'est renvoyer à une bibliographie pointue écrite il y a parfois longtemps en français.

Les incursions en grec sont également sujettes à révision. C'est dommage de réciter une nouvelle fois le livret bien modeste de Basile de Césarée sans se reporter aux legs bien plus intéressants de Clément d'Alexandrie et surtout aux commentaires richissimes qu'en a donnés H.-I. Marrou dans sa longue introduction à son édition des Sources Chrétiennes. Mais ceci engage tout un débat qui sortirait d'un simple compte rendu.

En conclusion cet ouvrage se lit avec plaisir et bonheur. Il fait honneur à l'érudition de son auteur et à son désir d'enseigner. Il ne bouleverse pas notre savoir déjà acquis et sur un certain nombre de points il mériterait quelque controverse. Mais il peut entrer dignement dans les bonnes bibliothèques.

Michel BANNIARD (École Pratique des Hautes Études - Université Paris IV Sorbonne) 